\title{
OSTEO-ARTICULAR DISORDER IN CHILDREN WITH CYSTIC FIBROSIS
}

\author{
Dana-Teodora Anton-Paduraru', Ana-Simona Drochioi', Oana Teslariu', \\ Alina Mariela Murgu², Ioana Cernescu ${ }^{3}$, Alexandra-Dana Ifrim ${ }^{4}$, \\ Laura Mihaela Trandafir ${ }^{1}$ \\ ${ }^{1} 3^{\text {rd }}$ Clinic of Pediatrics, "G.T. Popa" University of Medicine and Pharmacy, Iasi \\ ${ }^{2} 2^{\text {nd }}$ Clinic of Pediatrics, "G.T. Popa" University of Medicine and Pharmacy, Iasi \\ 3 "Sf. Maria" Children's Emergency Hospital, Iasi \\ 4 "G.T. Popa" University of Medicine and Pharmacy, Iasi
}

\begin{abstract}
Osteo-articular disorder in cystic fibrosis is considered a common complication of this pathology. The most efficient strategies used for bone health maintenance in patients with cystic fibrosis are early recognition, prevention and correct treatment. The purpose of this study was the clinical and paraclinical evaluation of patients hospitalized in the $3^{\text {rd }}$ Clinic of Pediatrics, "Sf. Maria" Children's Emergency Hospital lasi, diagnosed with cystic fibrosis that exhibited also symptoms of osteo-articular manifestation. The results from this study support the idea that the association of treatment, calcium, multimineral supplements with appropriate hygienic-dietary regimen and with the background therapy of the disease can contribute significantly to better healthand wellbeing. Also, non-compliance to treatment among patients and their families significantly contributes to early installation of the complications, including the osteo-articular ones (even from the age of 6 years).
\end{abstract}

Keywords: cystic fibrosis, osteo-articular complication, child

\section{INTRODUCTION}

The cystic fibrosis (CF) is the most frequent monogenic autosomal recessive disorder found in Caucasian populations, characterized by clinical pleomorphism and progressive chronic evolution, potentially lethal (5).

The osteo-articular complication was first described in 1979 and in present it is considered a common complication in which the quantity and quality of the bone mineral is diminished. The most efficient strategies used for bone health maintenance in patients with cystic fibrosis are early recognition, prevention and correct treatment (2).

\section{OBJECTIVES}

The identification, clinical and paraclinical evaluation and the response to the specific treatment of the osteo-articular manifestationsthat accompany CF.

\section{MATERIALS AND METHODS}

A retrospective study was performed on a lot of 43 patients aged between 2 days and 18 years diagnosed with CF in the $3{ }^{\text {rd }}$ Clinic of Pediatrics, "Sf. Maria" Children Emergency Hospital Iasi.

The study protocol included:

- the criteria on which the CF diagnostic was based.

- the medical history, i.e.: age, sex, anthropometric indices-height, weight.

- the clinical and biological evolution resulting from the laboratory tests.

- the causes of the osteo-articular complications.

- the clinical symptoms (the severity of the malabsorption, respiratory symptoms, symptoms of osteo-articular disorder and the onset age).

- the correlation between the osteo-articular manifestations and the frequency of the respiratory infections. 
- the investigation of the bone disorder: calcium, phosphorus, alkaline phosphatase, serum 25-hydroxy-vitamin D concentration, osteodensitometry, long-bone radiographs, thoracic spine radiograph or fist radiography.

- investigations needed to rule out other forms of arthritis,

- the treatment (background therapy for CF, corticotherapy, anti-inflammatory, vitamin D) and treatment adherence.

- the evaluation of the response to therapy.

- the education and conciliation of the patients and their families.

\section{RESULTS}

The age distribution of the patients from the lot studied showed that the majority of patients with CFwere between 9-18 years of age (51\%) and only $5 \%$ were infants. Regarding gender distribution, a higher frequency of the disease was found in boys (67\%).

Bone manifestations were present at 7 from the 43 patients: initial signs were characteristic to rickets, then demineralization of the bone progressed up to osteoporosis in advanced stages. Also, postural defects such as dorsal kyphosis, asthenic chest, lordosis, painful muscular contractures, monoarthritis/oligoarthritis and digital clubbing were identified, Table 1.

TABLE 1. Osteo-articular manifestations in the studied lot

\begin{tabular}{|l|c|c|}
\hline $\begin{array}{l}\text { Signs and symptoms of the } \\
\text { osteo-articular disorder }\end{array}$ & $\begin{array}{c}\text { Number of } \\
\text { cases }\end{array}$ & Percentage \\
\hline Kyphoscoliosis & 5 & $12 \%$ \\
\hline Painful muscular contractures & 5 & $12 \%$ \\
\hline Monoarthritis & 1 & $2 \%$ \\
\hline Oligoarthritis & 1 & $2 \%$ \\
\hline Limb paresthesia & 3 & $8 \%$ \\
\hline Tooth decay & 6 & $15 \%$ \\
\hline Rosary rib & 5 & $13 \%$ \\
\hline Breastbone in hull & 3 & $8 \%$ \\
\hline Chest flared at the bottom & 2 & $5 \%$ \\
\hline Micrognathia & 1 & $3 \%$ \\
\hline Craniofacial dysmorphia & 2 & $5 \%$ \\
\hline
\end{tabular}

The articular manifestations varied from mild arthralgia ( 5 cases) to arthritis ( 2 cases), usually with symmetric distribution ( 5 cases) that interested the following articulations: ankles -2 cases, knee -3 cases, fist -1 case, elbow -1 case, metacarpophalangeal -2 cases. The onset was insidious, like a dull pain (5 cases) or an episodic joint pain. The symptoms recur when the respiratory function deteriorates ( 2 cases). In these 2 cases we observed the aggravation of the symptoms during the exacerbation of the pulmonary infection with Pseudomonas aeruginosa. Five patients from the lot studied presented digital clubbing, characteristic sign of OAHP.

The osteo-articular manifestations weredebuted after 5-10 years from the diagnostic of CF.

The analysis of nutritional status showed that 14 patients exhibited different degrees of dystrophy (3 cases - dystrophy $1^{\text {st }}$ degree, 5 cases- dystrophy $2^{\text {nd }}$ degree, 6 cases - dystrophy $3^{\text {rd }}$ degree) and 23 cases - ponderal hypotrophy. Seven patients with CF and osteo-articular manifestations presented the alteration of nutritional status and 4 of them presented signs of severe malabsorption.

The causes of vitamin D deficiency were malabsorption, insufficient intake and insufficient exposure to the sun, Table 2.

TABLE 2.The causes of vitamin D deficiency in the studied lot

\begin{tabular}{|l|c|c|}
\hline $\begin{array}{l}\text { The cause of vitamin D } \\
\text { deficiency }\end{array}$ & $\begin{array}{c}\text { Number of } \\
\text { cases }\end{array}$ & Percentage \\
\hline Malabsorption & 4 & $44 \%$ \\
\hline Insufficient intake & 3 & $33 \%$ \\
\hline Insufficient exposure to the sun & 2 & $22 \%$ \\
\hline
\end{tabular}

The analysis of the serum levels of calcium, phosphorus and alkaline phosphatase at all the patients with CF showed: hypocalcemia at $34 \%$ of patients, hypophosphatemia at $31 \%$ of patients and increase of alkaline phosphatase at $26 \%$ of the patients.

The level of vitamin D was determined at 29 from the 43 patients (the optimal serum concentration of 25-hydroxivitamin D is between $30-50 \mathrm{ng} /$ $\mathrm{mL})$, Table 3.

TABLE 3. Serum concentration of 25- hydroxivitamin $D$ in the studied lot

\begin{tabular}{|l|c|c|}
\hline $\begin{array}{l}\text { Serum concentration of } \\
\text { 25-hydroxivitamin D }\end{array}$ & $\begin{array}{c}\text { Number of } \\
\text { cases }\end{array}$ & Percentage \\
\hline Under $10 \mathrm{ng} / \mathrm{mL}$ & 1 & $3 \%$ \\
\hline $10-20 \mathrm{ng} / \mathrm{mL}$ & 8 & $28 \%$ \\
\hline $20-100 \mathrm{ng} / \mathrm{mL}$ & 20 & $69 \%$ \\
\hline
\end{tabular}

The measurement of the bone density was performed using osteodensitometry. This is an accurate method for the diagnose of osteoporosis, and also an accurate estimator for the risk of fractures. Table 4 presents the results of thestudied lot.

All 7 patients with osteo-articular manifestationsshowed diminished levels of Z-score: 4 patients - osteopenia, 3 patients - osteoporosis. The 3 patients with osteoporosis presented severe osteo- 
TABLE 4. The modifications of osteodensitometry in the studied lot

\begin{tabular}{|l|c|c|}
\hline Results of osteodensitometry & $\begin{array}{c}\text { Number of } \\
\text { cases }\end{array}$ & Percentage \\
\hline Normal & 10 & $56 \%$ \\
\hline $\begin{array}{l}\text { Osteopenia } \\
\text { (score Z between }-1 \text { and }-2,5 \text { ) }\end{array}$ & 6 & $33 \%$ \\
\hline Osteopenia (score $Z \geq-2,5$ ) & 3 & $11 \%$ \\
\hline
\end{tabular}

articular symptomatology and increased levels of alkaline phosphatase and decreased levels of calcium and phosphorus in comparison with the patients with osteopenia. Table 5 indicates the radiologic modifications of the lot studied.

TABLE 5. The radiologic modification identified in the studied lot

\begin{tabular}{|l|c|c|}
\hline Radiologic modification & $\begin{array}{c}\text { Number } \\
\text { of cases }\end{array}$ & Percentage \\
\hline Periostitis of distal ends of long bones & 5 & $18 \%$ \\
\hline $\begin{array}{l}\text { Metaphyses of long bones, dilated } \\
\text { appearance, in cup }\end{array}$ & 6 & $22 \%$ \\
\hline $\begin{array}{l}\text { Metaphyseal concave line with } \\
\text { irregular edge }\end{array}$ & 6 & $21 \%$ \\
\hline Lateral spikes & 4 & $14 \%$ \\
\hline Delay in the ossification of the nucleus & 4 & $14 \%$ \\
\hline Kyphosis & 3 & $11 \%$ \\
\hline
\end{tabular}

The 2 cases with arthritis showed multiple radiologic modifications: metaphyses of long bones, dilated appearance, in cup, delay in the ossification of the nucleus and lateral spikes. All patients had radiologic modifications, including patients with cystic fibrosis, apparently normal, without obvious clinic osteo-articular manifestations.

The treatment of the bone disorder targeted first the correction of malabsorption and malnutrition, the supplementation with vitamins, minerals and oligo-elements. $(4,16,17)$

The medical treatment included:

1. substitution treatment with pancreatic enzymes $\left(\right.$ Kreon $\left.^{\circledR}\right)$.

2. treatment of pulmonary infections according to the antibiogram.

3. treatment of the vitamin D deficiency, of the rickets, osteopenia or osteoporosis by:

- administration of supplements with vitamin $\mathrm{D}$, in the form of drops/tablets containing cholecalciferol or in injectable form for the patients with severe malabsorption.

- administration of supplements with calcium in association with vitamin $\mathrm{D}$ or in the form of multimineral complexes $(\mathrm{Ca}+$ $\mathrm{Mg}+\mathrm{Zn}+$ vitamin D) 5-10 $\mathrm{ml} \times 2$ 2-3 times per day.
The OAHP treatment of the patients from the studied lot consisted in rest, administration of nonsteroidal anti-inflammatory (Acetaminophen, Ibuprofen $20-40 \mathrm{mg} / \mathrm{kg} /$ day, corticotherapy, 7 days), simultaneously with the treatment of the respiratory affection (18).

After establishing the diagnostic and the establishment of the therapeutic measurements, the evolution of the patients with osteo-articular disorder was:

- persistency of a certain degree of osteopenia going up to severe osteoporosis in the cases of persistent malabsorption.

- exacerbation of AFC and OAHP associated with the deterioration of the pulmonary function in one case.

It has been also made the prophylaxis of exacerbations and relapses

\section{DISCUSSIONS}

The arthritis from CF was first described by Ansell and Newman. The main types of arthritis that appear in $\mathrm{CF}$ arearthropathy from cystic fibrosis (ACF) and hypertrophic pulmonary osteoarthropathy (OAHP), which represent important causes of morbidity $(13,14)$.

The arthropathy from cystic fibrosis (ACF) the most frequent form of arthritis from $\mathrm{CF}$, clinically manifested as a recurrent asymmetric monoor polyarthritis that affects especially the knees (3). The prevalence of ACF is between 2-8,5\%, 13,6 years old being theaverage age of onset of the illness, but this could be overrated because of the possibility of undiagnosed cases (6). There is no formal definition of the arthritis from $\mathrm{CF}$, but this disease has distinct symptoms such as: recurrent episodes of joint pain and tumefaction, especially at the knee and ankle joints, sensitivity and movement limitation, which are disabling for the patient. The pain develops in 12-24 hours and lasts between 5-7 days and the symptoms may disappear completely between the exacerbations (8).

Hypertrophic pulmonary osteoarthropathy or Bamberger-Marie osteoarthropathy is less frequent then ACF, with a prevalence between $2-7 \%$. It mainly affects males (12). The clinic symptoms include: digital clubbing (deformation - "drummer fingers"), bone and articular manifestations and cutaneous manifestations $(15,22)$.

In our study the prevalence of the joint manifestations was of $16.27 \%$. The disease was more frequent in boys, confirming the dates from the literature. However, in the medical literature the male 
gender is considered a more favorable factor than the female gender.

Several studies support the idea that the patients with cystic fibrosis have a decreased risk to damage the balance of calcium that affects bone health, the finding being confirmed also by this study (34\%) (1). The recommended calcium intake varies between $500 \mathrm{mg} /$ day for patients aged between 1-3 years, $800 \mathrm{mg} /$ day for children between $4-8$ years and $100 \mathrm{mg}$ /day for children between 9-18 years $(7,9)$, this intake will increase the absorption of calcium.

It is recommended, at least one time per year, to determinate the serum concentrations of vitamin D and calcium. The ideal time is at the end of the winter because the values of vitamin $\mathrm{D}$ vary according to the season $(20,11)$. If this is not possible at least the interpretation of the results should be made depending on the season when the analyses was taken, the degree of sun exposure and if the patient uses sunscreen (10).

The radiography had an important role in the evaluation of the osteo-articular disorder, considering the fact that radiologic signs appear early, they are present in the state in which clinical signs are

\section{REFERENCES}

1. Ferguson J.H., Chang A.B. Vitamin D supplementation for cystic fibrosis (Review) în The Cochrane Library 2011; John Wiley\&Sons, Ltd:1-11.

2. Haworth C.S. Impact of cystic fibrosis on bone health. Curr Opin Pulm Med 2010; 16(102): 516-622.

3. Javier R.M., Jacquot J. Bone disease in cystic fibrosis: What's new? Joint Bone Spine 2011; 78(33): 445-450.

4. Paccou J., Zeboulon N., Combescure C., Gossec L., Cortet B. The prevalence of osteoporosis, osteopenia, and fractures among adults with cystic fibrosis: a systematic literature review with metaanalysis. Calcif Tissue Int. 2010; 86: 1-7.

5. Popa I., Pop L., Popa Zagorca, Cîlt Casandra. Ghid de management în Mucoviscidoză-Fibroza Chistică, Editura Brumar, Timisoara 2006: 9-71.

6. Sermet-Gaudelus I., Castanet M., Retsch-Bogart G., Aris R.M. Update on cystic fibrosis-related bone disease: a special focus on children. Paediatr Respir Rev. 2009; 10(3):134-142.

7. Tangpricha V., Kelly A., Stephenson A., Maguiness K., Enders J., Robinson K.A. et al. An Update on the Screening, Diagnosis, Management, and Treatment of Vitamin D Deficiency in Individuals with Cystic Fibrosis: Evidence-Based Recommendations from the Cystic Fibrosis Foundation. J Clin Endocrin Metab 2012: 97(4):2011-3050.

8. Sermet-Gaudelus I., Bianchi M.L., Garabedian M., Aris R., Morton A., Hardin D. et al. European cystic fibrosis bone mineralisation guidelines. J Cyst Fibros 2011; 10 (Suppl 2): S16-23.

9. Bianchi M.L., Assael B., Dubini A., et al. Treatment of low bone density in young people with cystic fibrosis: a multicentre, prospective, open-label observational study of calcium and calcifediol followed by a rare or absent and they are considered pathognomonic (21).

The exacerbations of the pulmonary infections must be treated rapidly in order to minimize the adverse effects of the inflammation on the bone.

\section{CONCLUSIONS}

The treatment with vitamin $\mathrm{D}$, calcium and multi-mineral supplements associated with hygiene-dietary regimen and the background therapy of the disease have significantly contributed in some cases to a better health condition, determining a better quality of life and an improvement in the osteo-articular disorder.

Also, in some cases the patient's non-compliance with the treatment, the interruption of the therapeutic schedule, the failure to respect the recommendations contribute to the appearance of early complications, especially the osteo-articular ones (even from the age of 6).

Osteodensitometry must be performed for all the patients with CF starting at the age of 10, once a year or every 1-3 years, but at least one test until 18 years $(23)$. randomised placebo-controlled trial of alendronate. Lancet Resp Med. 2013; 1(5): 377-385.

10. Bilezikian J.P., Raisz L.G., Rodan G.A. Principles of bone biology, $3^{\text {rd }}$ edition, Academic Press, San Diego, CA, 2008: 961-79.

11. Cranney A., Horsley T., O'Donnell S., Weiler H., Puil L., Ooi D. et al. Effectiveness and safety of vitamin $D$ in relation to bone health. Evid Rep Technol Assess 2007; 158:1-235.

12. Stalvey M., Clines M. CysticFibrosis-Related Bonde Disease: Insights into a Growing Problem. Curr Opin Endocrinol Diabetes Obes. 2013; 20(6): 547-552.

13. Paccou J., Fardellone P., Cortet B. Cystic fibrosis-related bone disease. Curr Opin Pulm Med 2013; 19(6): 681-686.

14. Nguyen S., Hojjati M. Review of current therapies for secondary hypertrophic pulmonary osteoarthropathy. Clin Rheumatol. 2011 Jan. 30(1):7-13.

15. Manger B., Lindner A., Manger K., Wacker J., Schett G. [Hypertrophic osteoarthropathy. Bamberger-Marie disease]. J Rheumatol. 2011 Sep. 70(7):554-60.

16. Braun A., Chang D., Mahadevappa K., Gibbons F.K., Liu Y., Giovannucci E., et al. Association of low serum 25-hydroxyvitamin D levels and mortality in the critically ill. Crit Care Med. 2011;39:671-7. doi: 10.1097/CCM.0b013e318206ccdf. [PMC free article] [PubMed] [Cross Ref]

17. West N.E., Lechtzin N., Merlo C.A., Turowski J.B., Davis M.E., Ramsay M.Z., et al. Appropriate goal level for 25-hydroxyvitamin D in cystic fibrosis. Chest. 2011; 140:469-74. doi: 10.1378/chest.10-2114. [PubMed] [Cross Ref]

18. Demoruelle M.K., Deane K.D., Holers V.M. When and where does inflammation begin in rheumatoid arthritis? Curr Opin Rheumatol. 
2014; 26:64-71. doi: 10.1097/BOR.0000000000000017. [PMC free article] [PubMed] [Cross Ref]

19. Sermet-Gaudelus I., Bianchi M.L., Garabedian M., et al. European cystic fibrosis bone mineralisation guidelines. J Cyst Fibros. 2011; 10(Suppl 2):S16-S23. [PubMed]

20. Ross A.C., Taylor C.L., Yaktine A.L., et al., editors. Dietary Reference Intakes for Calcium and Vitamin D. Washington (DC): 2011.

21. Grey V., Atkinson S., Drury D., et al. Prevalence of low bone mass and deficiencies of vitamins $D$ and $K$ in pediatric patients with cystic fibrosis from 3 Canadian centers. Pediatrics. 2008; 122:1014-1020 [PubMed]

22. Rossini M., Del Marco A., Dal Santo F., et al. Prevalence and correlates of vertebral fractures in adults with cystic fibrosis. Bone. 2004; 35:771-776 [PubMed]

23. Cystic Fibrosis Foundation Patient Registry, 2011. Anual Data Report. Bethesda, Maryland: 2012. ${ }^{* *}$ A detailed account of the CF Foundation Patient Registry, with data on incidence of comorbidities in CF. 